\title{
Visceral fat obesity is highly associated with primary gout in a metabolically obese but normal weighted population: a case control study
}

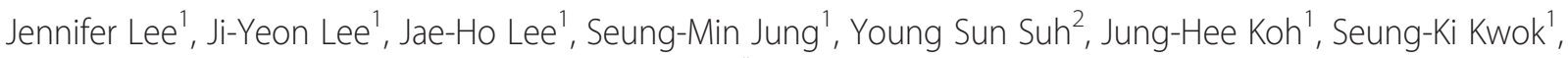
Ji Hyeon Ju' ${ }^{1}$ Kyung-Su Park ${ }^{3}$ and Sung-Hwan Park ${ }^{1 *}$

\begin{abstract}
Introduction: Gout is a chronic inflammatory disease the development of which is associated with obesity-induced metabolic abnormalities. However, a substantial number of non-obese patients (body mass index [BMl] $<25 \mathrm{~kg} / \mathrm{m}^{2}$ ) also develop gout in Korea. It was suggested that accumulation of visceral fat rather than subcutaneous fat is associated with metabolic abnormalities and hyperuricemia in patients with gout; therefore, we hypothesized that visceral fat accumulation was increased in non-obese gout patients.

Methods: One hundred and three male patients with primary gout and 204 age-matched healthy controls who attended a health check-up examination were recruited after the review of medical charts. The visceral fat area (VFA) was measured using the bioelectrical impedance analysis (BIA) method, and a VFA $>100 \mathrm{~cm}^{2}$ was defined as visceral fat obesity (VFO). The frequency of VFO was compared in patients and control groups. The frequencies of metabolic syndrome and related parameters were also investigated.

Results: BMI, waist circumference, total fat mass, serum triglycerides, and serum glucose levels were significantly greater in patients compared with controls. VFA and the prevalence of VFO was increased in gout patients compared with controls. There were positive correlations between VFA and serum triglyceride levels and serum glucose levels. Multivariate regression analysis revealed that VFO is an independent risk factor for gout (odds ratio 2.488, 95\% confidence interval 1.041-4.435). In non-obese subgroup analyses (gout patients, $n=38$; healthy controls, $n=150)$, VFA ( $98.7 \pm 19.3$ vs. $91.0 \pm 16.7, P=0.016)$ and the frequency of VFO (47.4 vs. $27.3 \%, P=0.017)$ remained significantly higher in gout patients. There was no difference in either BMl or total fat mass between patients and controls in the non-obese subgroup. The prevalence of metabolic syndrome in patients with gout was $31.7 \%$ (33/104), compared with 13.2\% (5/38) in the non-obese subgroup according to modified ATP III criteria.
\end{abstract}

Conclusion: VFO, measured using BIA, is observed more frequently in patients with primary gout compared with healthy controls, even in non-obese individuals. Therefore, VFO might more properly represent metabolic derangements in patients with gout than general obesity.

\section{Introduction}

Gout is a prototypic of crystal-induced arthropathy caused by monosodium urate (MSU) crystal precipitation in joints. Although the precise mechanism of disease pathogenesis remains unclear, hyperuricemia is a prerequisite of gout development. In addition, the inflammasome, intracellular

\footnotetext{
* Correspondence: rapark@catholic.ac.kr

'Division of Rheumatology, Department of Internal Medicine, School of Medicine, The Catholic University of Korea, Seoul St. Mary's Hospital, 222 Banpo-daero, Seocho-gu, Seoul 137-701, Republic of Korea

Full list of author information is available at the end of the article
}

machinery related to innate immunity, plays an important role in producing IL-1 $\beta$, which is the critical cytokine for MSU-induced gout inflammation [1]. The history of gout spans thousands of years, and it was historically referred to as a king's disease because its development is closely associated with the consumption of large amounts of fatty foods and alcohol, as well as obesity. Indeed, several studies reported a close relationship between fat accumulation and gout/hyperuricemia [2-6]. Furthermore, gout patients are not only obese but also commonly have obesity-associated comorbidities such as high blood 
pressure, hypertriglyceridemia, or impaired fasting glucose, which together comprise metabolic syndrome [7]. In line with this, the prevalence of metabolic syndrome is higher in gout patients compared with the general population [8-14].

These observations suggest that obesity is a strong risk factor for the development of gout. However, in Korea, there are a substantial number of non-obese gout patients (body mass index $(\mathrm{BMI})<25 \mathrm{~kg} / \mathrm{m}^{2}$ ). It was suggested that the accumulation of visceral fat rather than subcutaneous fat is associated with metabolic abnormalities and hyperuricemia in patients with gout [4]; therefore, we hypothesized that visceral fat accumulation was increased in non-obese gout patients and that this resulted in metabolic derangements that caused these individuals to be more prone to gout. In the present study, we investigated the association between visceral fat obesity and the development of gout, focusing particularly on a non-obese population, and characterized metabolic syndrome-related parameters in obese and non-obese subgroups of gout patients.

\section{Methods}

\section{Study population}

One hundred and three patients who were diagnosed with gout according to the 1977 American College of Rheumatology preliminary criteria for gout [15] were recruited between March 2009 and Dec 2013 at Seoul St Mary's hospital, Seoul, Korea. Two hundred and four age-matched healthy individuals who attended routine health check-up examinations during the same period were included as controls. Retrospective medical chart reviews were performed to obtain clinical and laboratory data; thereby, no consent was needed from the study population. The Institutional Review Board of the School of Medicine, Catholic University, approved the study protocol.

\section{Clinical information and laboratory analysis}

The clinical information was obtained from electronic medical records of all patients, including medical history, the use of medications, and laboratory data. Anthropometric variables (height and weight) were measured when subjects were in the standing position. BMI was calculated as weight in $\mathrm{kg}$ divided by the square of height in meters $\left(\mathrm{kg} / \mathrm{m}^{2}\right)$. Blood pressure was measured in the sitting position (in $\mathrm{mmHg}$ ). The visceral fat area (VFA) was determined using the bioelectrical impedance analysis (BIA) method with Inbody 720 (Biospace, Seoul, Korea) according to the manufacturer's instructions. Fasting venous blood samples were taken to measure the serum levels of total cholesterol, high-density lipoprotein (HDL) cholesterol, low-density lipoprotein (LDL) cholesterol, triglycerides, glucose, and uric acid.

\section{Definitions}

General obesity was defined as a BMI $>25 \mathrm{~kg} / \mathrm{m}^{2}$ because the study population was Asian. Visceral fat obesity (VFO) was defined as a VFA $>100 \mathrm{~cm}^{2}$ according to a previous report [5]. The presence of metabolic syndrome was defined according to the modified ATP (Adult Treatment Panel) III criteria, in which the waist circumference criterion was adjusted to $\geq 90 \mathrm{~cm}$ in males and $\geq 80 \mathrm{~cm}$ in females according to the World Health Organization (WHO) Asia-Pacific obesity criteria (APC) [16]. All other components were the same as in the ATP III criteria [17], where the presence of metabolic syndrome was defined as having at least three of the following five parameters: a waist circumference $>102 \mathrm{~cm}$ for males or $>88 \mathrm{~cm}$ for females, serum triglyceride levels $\geq 150 \mathrm{mg} / \mathrm{dL}$, serum HDL cholesterol levels $<40 \mathrm{mg} / \mathrm{dL}$ for males or $<50 \mathrm{mg} / \mathrm{dL}$ for females, systolic blood pressure $\geq 130 \mathrm{mmHg}$ or diastolic blood pressure $\geq 85 \mathrm{mmHg}$, and fasting blood glucose $\geq 110 \mathrm{mg} / \mathrm{dL}$.

\section{Statistics}

Statistical analyses were performed using the SAS software, version 9.0 (SAS, Cary, NC, USA), and data are presented as mean \pm standard deviation or median (interquartile range). Data were compared using the Student's $t$-test or the Mann-Whitney $U$-test for continuous variables, and the Chi-square test for categorical variables. Spearman's correlation coefficient was calculated for correlation analysis. Multivariate logistic regression analysis was used to identify independent risk factors for the development of gout, and the results are presented as odds ratio (OR) with $95 \% \mathrm{CI}$. A value of $P<0.05$ was used to indicate statistical significance.

\section{Results}

Clinical and laboratory characteristics of the subjects

A total of 104 gout patients and 203 age-matched healthy controls were recruited. Table 1 shows the clinical and laboratory characteristics of the subjects. All the subjects were male, and the mean age was comparable between groups (51.0 (16) years for gout patients versus 51.0 (14) years for healthy controls). Among 104 gout patients, 72 were taking a urate-lowering agent at the time of body composition analysis; 28 patients were taking anti-hypertensive medication, and 11 were on a glucose-lowering agent due to diabetes mellitus, and 39 patients were taking a lipid-lowering agent such as statins or omega-3 fatty acids. Gout patients had a significantly higher mean BMI (25.8 (4.6) versus 23.5 (3.1) $\mathrm{kg} / \mathrm{m}^{2}, P<0.001$ ), VFA, waist/hip circumference, total fat mass and percent mass, blood pressure, serum uric acid levels, serum triglycerides, and glucose levels. In particular, the frequency of VFO was higher in gout patients (71.8 versus $41.2 \%, P<0.001$ ). There were no differences 
Table 1 Clinical and laboratory characteristics of the subjects

\begin{tabular}{|c|c|c|c|}
\hline & $\begin{array}{l}\text { Gout } \\
(n=103)\end{array}$ & $\begin{array}{l}\text { Healthy } \\
(n=204)\end{array}$ & $P$ \\
\hline Age, years & $51.0(16)$ & $51.0(14)$ & $0.944^{*}$ \\
\hline Body mass index, $\mathrm{kg} / \mathrm{m}^{2}$ & $25.8(4.6)$ & $23.5(3.1)$ & $<0.001^{*}$ \\
\hline Visceral fat area, $\mathrm{cm}^{2}$ & $115.6 \pm 25.3$ & $97.7 \pm 20.2$ & $<0.001$ \\
\hline Visceral fat obesity, VFA $\geq 100 \mathrm{~cm}^{2}$ & $74(71.8 \%)$ & $84(41.2 \%)$ & $<0.001$ \\
\hline Waist circumference, $\mathrm{cm}$ & $91.2 \pm 9.7$ & $82.3 \pm 7.5$ & $<0.001$ \\
\hline Hip circumference, $\mathrm{cm}$ & $99.2 \pm 7.4$ & $94.0 \pm 4.5$ & $<0.001$ \\
\hline Total fat mass, kg & $20.1(10.3)$ & $14.9(5.4)$ & $<0.001^{*}$ \\
\hline Total fat percentage, $\%$ & $25.6 \pm 5.7$ & $21.7 \pm 4.4$ & $<0.001$ \\
\hline Systolic blood pressure, $\mathrm{mmHg}$ & $125.0 \pm 13.8$ & $118.5 \pm 12.1$ & $<0.001$ \\
\hline Diastolic blood pressure, $\mathrm{mmHg}$ & $80.4 \pm 11.1$ & $75.7 \pm 9.9$ & 0.001 \\
\hline Uric acid, mg/dL & $7.9 \pm 1.9$ & $6.4 \pm 6.0$ & 0.001 \\
\hline Total cholesterol, mg/dL & $191.2 \pm 37.0$ & $192.0 \pm 27.2$ & 0.857 \\
\hline Triglyceride, mg/dL & $155.0(118)$ & $82.0(52.0)$ & $<0.001^{*}$ \\
\hline High-density lipoprotein, mg/dL & $44.0(15.0)$ & $51.0(15.0)$ & $<0.001^{*}$ \\
\hline Low-density lipoprotein, mg/dL & $114.3 \pm 32.5$ & $119.1 \pm 25.5$ & 0.159 \\
\hline Glucose, mg/dL & $96.4(16.0)$ & $89.0(10.0)$ & $<0.001^{*}$ \\
\hline
\end{tabular}

*Non-parametric Mann-Whitney U-test was used.

mean \pm standard deviation or median (interquartile range).

in the serum level of total cholesterol or LDL cholesterol between the two groups.

\section{Visceral fat obesity is an independent risk factor for the development of gout}

VFA was correlated positively with age (Spearman's rho: $0.426, P<0.001)$ and other metabolic syndrome-associated factors including waist circumference (Spearman's rho: 0.799, $P<0.001$ ), serum fasting glucose levels (Spearman's rho: $0.324, P<0.001$ ) and triglycerides (Spearman's rho: 0.274, $P<0.001$ ) (Figure 1), suggesting that VFA reflects metabolic factors accurately. Furthermore, because we observed that the frequency of VFO was significantly higher in gout patients compared with controls, we next investigated whether VFO was an independent risk factor for gout. Multivariate logistic regression analysis of variables including age, the presence of obesity (BMI $\geq 25$ versus BMI $<25 \mathrm{~kg} / \mathrm{m}^{2}$ ), the presence of hypertriglyceridemia $(\geq 150 \mathrm{mg} / \mathrm{dL}$ versus $<150 \mathrm{mg} / \mathrm{dL}$ ), and the presence of VFO revealed that VFO was an independent risk factor for gout development (OR 2.488, 95\% CI 1.041, 4.435) (Table 2). Obesity was also an independent risk factor, consistent with previous reports that reported a close association between obesity and gout $[18,19]$.

\section{Metabolic derangements in non-obese gout patients} Subgroup analyses were performed to investigate whether metabolic derangements were present in both obese and non-obese gout patients. A total of 38 of the 104 gout patients (36.5\%) had BMI $<25 \mathrm{~kg} / \mathrm{m}^{2}$, and their clinical and laboratory characteristics were compared with those of non-obese healthy controls ( $\mathrm{n}=150 / 203,69.0 \%)$ (Table 3). Although BMI was comparable between groups (23.4 (2.0) $\mathrm{kg} / \mathrm{m}^{2}$ for gout patients versus 22.7 (2.4) $\mathrm{kg} / \mathrm{m}^{2}$ for healthy controls, $P=0.127$ ), VFA (98.7 \pm 19.3 versus $\left.91.0 \pm 16.7 \mathrm{~cm}^{2}, P=0.016\right)$ and the frequency of VFO (47.4 versus $27.3 \%, P=0.017$ ) were higher in gout patients. Non-obese gout patients also had significantly higher serum triglyceride (127.0 (94.0) versus 81.0 (52.0) $\mathrm{mg} / \mathrm{dL}, P<0.001)$ and glucose $(97.3 \pm 13.0$ versus $89.0 \pm$ $6.8 \mathrm{mg} / \mathrm{dL}, P<0.001)$ levels compared with non-obese normal individuals. Of note, total fat mass (14.3 (4.5) versus $13.5(4.1) \mathrm{kg}, P=0.271)$ and the total fat percentage (21.1 \pm 4.7 versus $20.4 \pm 3.8 \%, P=0.295)$ were not different between the two subgroups. Collectively, these results suggest that metabolic derangements occur in nonobese gout patients, and that visceral fat accumulation rather than the amount of total fat is associated with this phenomenon.

\section{Prevalence of metabolic syndrome and the fulfillment of related parameters}

The prevalence of metabolic syndrome in gout patients was $31.7 \%$ (33/104) according to the modified ATP III criteria. Table 4 shows which components of metabolic syndrome were present in the current study subjects. In non-obese subgroup analyses, the prevalence of metabolic syndrome was $13.2 \%$. Interestingly, only one patient $(1 / 38$, $2.6 \%$ ) had a waist circumference $\geq 90 \mathrm{~cm}$, whereas the frequency of VFO was $47.4 \%$ (18/38). The frequency of hypertriglyceridemia, elevated blood pressure, and impaired fasting glucose was significantly higher in gout patients.

\section{Discussion}

In the present study, we demonstrated that VFA, measured using BIA, was greater in gout patients compared with healthy controls. VFO was more prevalent in nonobese gout patients compared with non-obese controls. Furthermore, metabolic derangements according to the components of metabolic syndrome were also present in non-obese gout patients.

Consistent with previous studies suggesting that adipose tissue plays an important role in gout $[4,9,12-14,20]$, the current data also demonstrated that obesity is an independent risk factor for gout. In particular, the accumulation of visceral fat was detrimental, even in patients without general obesity. Although the precise molecular mechanism behind this phenomenon remains unclear, the contribution of fat accumulation to the development of gout has two possible explanations. First is the traditional correlation between fat accumulation and hyperuricemia. It has been reported that fat affects uric acid metabolism 


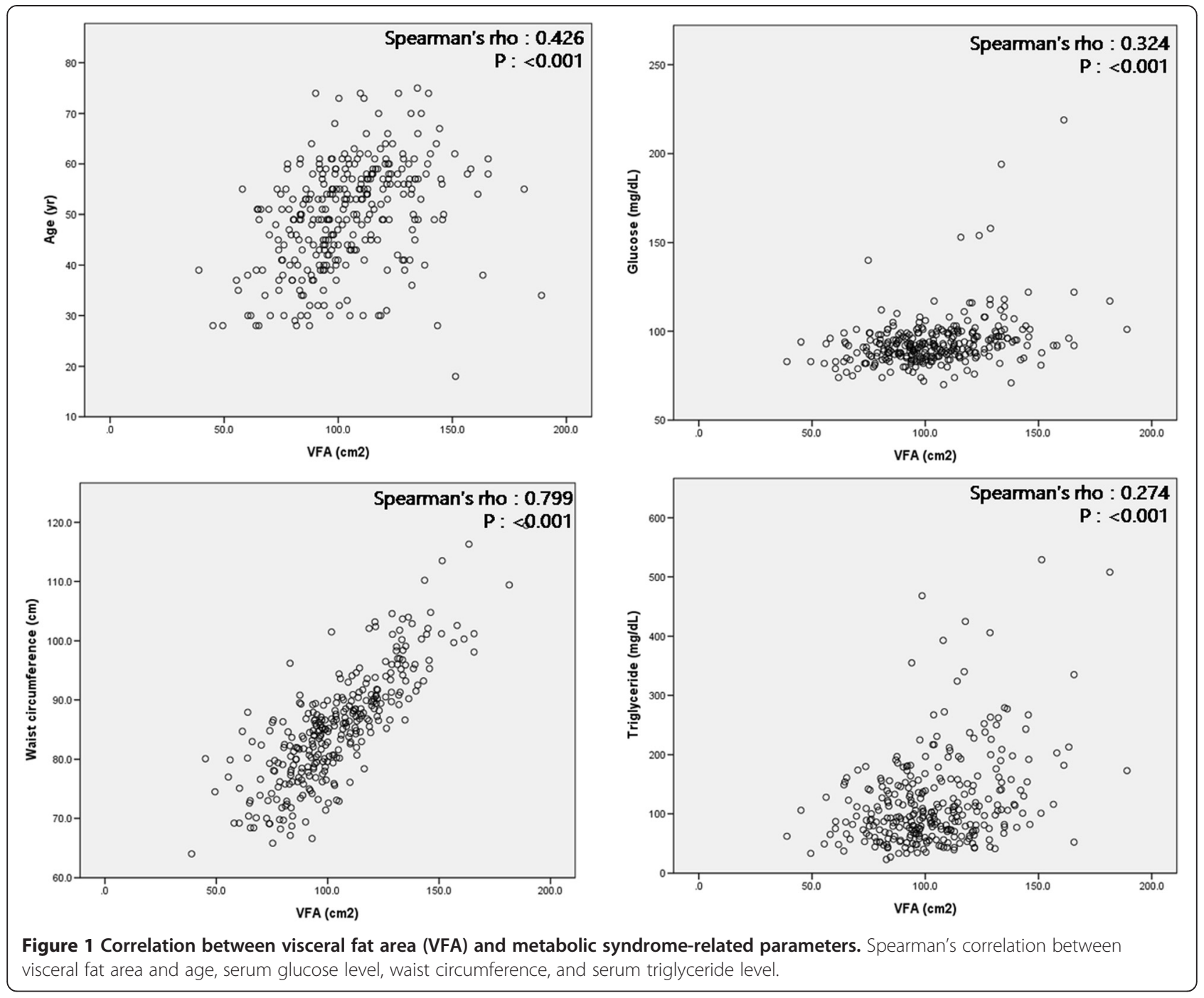

and results in increased serum uric acid levels [2,3,20,21]. However, we did not identify any associations between the fat accumulation and serum uric acid levels. This discrepancy might be because most of the patients were taking uric acid-lowering agents as well as the relatively small sample size of the study. The second explanation is that the production of adipokines by fat tissue, such as IL-6

Table 2 Multivariate logistic regression analysis for the development of gout

\begin{tabular}{lllll}
\hline & $\boldsymbol{\beta}$ & $\begin{array}{l}\text { Standard } \\
\text { error }\end{array}$ & Odds ratio & $\mathbf{9 5 \% ~ C l}$ \\
\hline Age & -0.009 & 0.016 & 0.991 & $0.961,1.022$ \\
$\begin{array}{l}\text { Body mass index } \\
\geq 25 \mathrm{~kg} / \mathrm{m}^{2}\end{array}$ & 0.911 & 0.773 & 2.488 & $1.298,4.770$ \\
$\begin{array}{l}\text { Visceral fat area } \\
\geq 100 \mathrm{~cm}^{2}\end{array}$ & 0.765 & 0.37 & 2.149 & $1.041,4.435$ \\
$\begin{array}{l}\text { Triglyceride } \\
\geq 150 \mathrm{mg} / \mathrm{dL}\end{array}$ & 2.007 & 0.32 & 7.442 & $3.972,13.943$ \\
\hline
\end{tabular}

and tumor necrosis factor- $\alpha$, enhances obesity-induced inflammation [22]. Importantly, these adipokines that promote inflammation are mainly produced by visceral rather than subcutaneous fat [23]. On the contrary, the level of adiponectin, an anti-inflammatory adipokine, is lower in individuals with VFO [24]. This adipokine profile supports the emphasis on VFO in the current study.

Recent studies suggested another possible explanation involving activation of the NLRP3 inflammasome and obesity-induced inflammation [15]. Triglycerides, the level of which was highly associated with VFO, are the source of fatty acids that stimulate toll-like receptor (TLR)-2 and can subsequently activate the inflammasome, which plays a central role in acute gout attacks [25]. In turn, the inflammasome enhances fat accumulation [26]. This suggests that this vicious cycle might be present in gout patients in whom the inflammasome is activated, although future studies are needed to confirm this hypothesis. 
Table 3 Clinical and laboratory characteristics of the non-obese subjects (BMI $<25 \mathrm{~kg} / \mathrm{m}^{2}$ )

\begin{tabular}{llll}
\hline & $\begin{array}{l}\text { Gout } \\
(\mathbf{n = 3 8 )}\end{array}$ & $\begin{array}{l}\text { Healthy } \\
(\mathbf{n}=\mathbf{1 5 0})\end{array}$ & $\boldsymbol{P}$ \\
\hline Age, years & $52.6 \pm 9.7$ & $49.2 \pm 10.8$ & 0.06 \\
Body mass index, kg/m² & $23.4(2.0)$ & $22.7(2.4)$ & $0.127^{*}$ \\
Visceral fat area, cm² & $98.7 \pm 19.3$ & $91.0 \pm 16.7$ & 0.016 \\
Visceral fat obesity, VFA $\geq 100 \mathrm{~cm}^{2}$ & $18(47.4 \%)$ & $41(27.3 \%)$ & 0.017 \\
Waist circumference, cm & $84.7(6.8)$ & $79.7(8.5)$ & $0.001^{*}$ \\
Hip circumference, cm & $92.9 \pm 4.9$ & $92.4 \pm 3.7$ & 0.403 \\
Total fat mass, kg & $14.3(4.5)$ & $13.5(4.1)$ & $0.271^{*}$ \\
Total fat percentage, \% & $21.1 \pm 4.7$ & $20.4 \pm 3.8$ & 0.295 \\
Systolic blood pressure, mmHg & $122.5 \pm 13.9$ & $117.5 \pm 13.1$ & 0.049 \\
Diastolic blood pressure, mmHg & $80.0(14.5)$ & $74.0(15.0)$ & $0.070^{*}$ \\
Uric acid, mg/dL & $7.9(1.3)$ & $6.0(1.3)$ & $<0.001^{*}$ \\
Total cholesterol, mg/dL & $193.1 \pm 33.8$ & $190.5 \pm 27.5$ & 0.746 \\
Triglyceride, mg/dL & $127.0(94.0)$ & $81.0(52.0)$ & $<0.001^{*}$ \\
High-density lipoprotein, mg/dL & $46.5(16.0)$ & $51.0(15.0)$ & $0.008^{*}$ \\
Low-density lipoprotein, mg/dL & $114.5(37.0)$ & $115.0(37.0)$ & $0.919^{*}$ \\
Glucose, mg/dL & $97.3 \pm 13.0$ & $89.0 \pm 6.8$ & $<0.001$ \\
\hline
\end{tabular}

*Non-parametric Mann-Whitney U-test was used.

mean \pm standard deviation or median (interquartile range).

The current study demonstrated that VFO was more prevalent in non-obese gout patients with BMI $<25 \mathrm{~kg} / \mathrm{m}^{2}$ compared with non-obese control subjects. Importantly, there was no difference in total fat mass or total fat percentage between gout patients and controls. Therefore, these data suggest that visceral obesity, regardless of general obesity, contributes to the pathogenesis of gout. In addition, non-obese gout patients had hypertriglyceridemia and were pre-hypertensive more frequently than healthy controls. Because the waist circumference of most individuals did not exceed $90 \mathrm{~cm}$, while $>25 \%$ of individuals exhibited VFO, visceral fat accumulation appears to represent central obesity and metabolic abnormality more accurately in this population. As the BIA method is a safer and more convenient method for measuring VFA compared with traditional computed tomography $(\mathrm{CT})$, it might be helpful for assessing and monitoring visceral fat accumulation in gout patients.

One interesting question is whether the presence of VFO affects the clinical manifestation of gout. For example, Gheita et al. demonstrated that bone erosion was more prevalent in gout patients with metabolic syndrome compared with those without metabolic syndrome [27]. However, there were no differences in the frequency of bone erosion at the affected joints in individuals with and without VFO in the current study (data not shown).

We verified that the prevalence of metabolic syndrome was higher in gout patients, which was consistent with previous studies $[8,10,12-14]$. The proinflammatory trait of the patients with metabolic syndrome suggested by Zhao et al. [28] who demonstrated that the level of highly sensitive C-reactive protein, an acute phase reactant, was higher in individuals with metabolic syndrome may contribute to gouty inflammation. Importantly, the current data revealed that a number of non-obese gout patients fulfilled the criteria for metabolic syndrome, albeit to a lesser extent than did obese patients. As mentioned above, most of these patients had a waist circumference $<90 \mathrm{~cm}$. Therefore, other components of metabolic syndrome are likely to be associated with VFO.

The current study has several limitations. First, measuring visceral fat using BIA might not be the gold-standard method. However, the device we used in this study was validated in comparisons with CT scans [29] and the accuracy of the BIA method is well-established [30-32]. Second, this is a retrospective study based on the review of medical charts, and had a relatively small sample size. However, an important strength of the current study is that we verified that visceral fat accumulation was present and represented metabolic abnormalities in non-obese gout patients. Therefore, this suggests that assessing and monitoring VFO might be required.

Table 4 Prevalence of the fulfillment of metabolic syndrome-related parameters

\begin{tabular}{|c|c|c|c|c|c|c|}
\hline & \multicolumn{3}{|c|}{ Body mass index $\geq 25$} & \multicolumn{3}{|c|}{ Body mass index $<25$} \\
\hline & $\begin{array}{l}\text { Gout } \\
(n=65)\end{array}$ & $\begin{array}{l}\text { Healthy } \\
(n=54)\end{array}$ & $P$ & $\begin{array}{l}\text { Gout } \\
(n=38)\end{array}$ & $\begin{array}{l}\text { Healthy } \\
(n=150)\end{array}$ & $P$ \\
\hline$W C \geq 90 \mathrm{~cm}$ & $50(76.9 \%)$ & $24(44.4 \%)$ & $<0.001$ & $1(2.6 \%)$ & $5(3.3 \%)$ & 0.826 \\
\hline $\mathrm{TG} \geq 150 \mathrm{mg} / \mathrm{dL}$ & $41(63.1 \%)$ & $6(11.1 \%)$ & $<0.001$ & $13(34.2 \%)$ & $15(10.0 \%)$ & $<0.001$ \\
\hline $\mathrm{HDL}<40 \mathrm{mg} / \mathrm{dL}$ & $28(43.1 \%)$ & $8(14.8 \%)$ & 0.001 & $10(26.3 \%)$ & $14(9.3 \%)$ & 0.011 \\
\hline$B P \geq 130 / 85$ & $31(47.7 \%)$ & $15(27.8 \%)$ & 0.026 & $15(39.5 \%)$ & $26(17.3 \%)$ & 0.003 \\
\hline Glucose $\geq 110 \mathrm{mg} / \mathrm{dL}$ & $15(23.1 \%)$ & $0(0 \%)$ & $<0.001$ & $5(13.2 \%)$ & $0(0 \%)$ & $<0.001$ \\
\hline modified ATP III & $28(43.1 \%)$ & 1 (1.9\%) & $<0.001$ & $5(13.2 \%)$ & $0(0 \%)$ & $<0.001$ \\
\hline
\end{tabular}

Results are presented as number (\%) of patients. BP: blood pressure; HDL: high density lipoprotein; TG: triglyceride; WC: waist circumference. 


\section{Conclusions}

VFO, as measured using BIA, was observed more frequently in both obese and non-obese patients with primary gout compared with healthy controls. VFA was correlated positively with components of metabolic syndrome. Therefore, VFO might more properly represent metabolic derangements in patients with gout than general obesity. Future studies addressing whether the risk of gout can be reduced by monitoring and losing visceral fat will be promising.

\section{Abbreviations}

APC: Asia-pacific obesity criteria; ATP: Adult Treatment Panel; BIA: bioelectrical impedance analysis; BMl: body mass index; HDL: high-density lipoprotein; IL: interleukin; LDL: low-density lipoprotein; MSU: monosodium urate; OR: odds ratio; TLR: Toll-like receptor; VFA: visceral fat area; VFO: visceral fat obesity.

\section{Competing interests}

The authors declare that they have no competing interests.

\section{Authors' contributions}

$J \mathrm{~L}$ contributed to the study design, data collection, data interpretation, and coordination of the study, and drafted the manuscript. JYL, JHL, SMJ, YSS, JHK, SKK, JHJ, and KSP contributed to data interpretation and analysis of the study. SHP contributed to study design, data interpretation, and analysis of the study. All authors contributed to discussions of the article content and review or editing of the manuscript before submission. All authors read and approved the manuscript.

\section{Acknowledgement}

This research was supported by Basic Science Research Program through the National Research Foundation of Korea (NRF) funded by the Ministry of Education, Science and Technology (NRF-2013R1A2A2A01007720)

\section{Author details}

'Division of Rheumatology, Department of Internal Medicine, School of Medicine, The Catholic University of Korea, Seoul St. Mary's Hospital, 222 Banpo-daero, Seocho-gu, Seoul 137-701, Republic of Korea. ${ }^{2}$ Department of Internal Medicine and Institute of Health Science, Gyeongsang National University School of Medicine, 79 Gangnam-ro, Jinju 660-702, Republic of Korea. ${ }^{3}$ Division of Rheumatology, Department of Internal Medicine, School of Medicine, The Catholic University of Korea, St. Vincent's Hospital, 93 Jungbu-daero (Ji-dong), Paldal-gu, Suwon, Gyeonggi-do 442-723, Republic of Korea.

Received: 6 November 2014 Accepted: 5 March 2015

Published online: 24 March 2015

\section{References}

1. Richette P, Bardin T. Gout. Lancet. 2010;375:318-28.

2. Cigolini M, Targher G, Tonoli M, Manara F, Muggeo M, De Sandre G. Hyperuricaemia: relationships to body fat distribution and other components of the insulin resistance syndrome in 38-year-old healthy men and women. Int J Obes Relat Metab Disord. 1995;19:92-6.

3. Takahashi S, Yamamoto T, Tsutsumi Z, Moriwaki Y, Yamakita J, Higashino K. Close correlation between visceral fat accumulation and uric acid metabolism in healthy men. Metabolism. 1997;46:1162-5.

4. Takahashi S, Yamamoto T, Tsutsumi Z, Moriwaki Y, Hada T. Increased visceral fat accumulation in patients with primary gout. Adv Exp Med Biol. 2000;486:131-4.

5. Takahashi S, Moriwaki Y, Tsutsumi Z, Yamakita J, Yamamoto T, Hada T. Increased visceral fat accumulation further aggravates the risks of insulin resistance in gout. Metabolism. 2001;50:393-8.

6. Tamba S, Nishizawa H, Funahashi T, Okauchi Y, Ogawa T, Noguchi M, et al. Relationship between the serum uric acid level, visceral fat accumulation and serum adiponectin concentration in Japanese Men. Int Med. 2008;47:1175-80.
7. Ichikawa N, Taniguchi A, Urano W, Nakajima A, Yamanaka H. Comorbidities in patients with gout. Nucleosides Nucleotides Nucleic Acids. 2011;30:1045-50.

8. Rho YH, Choi SJ, Lee YH, Ji JD, Choi KM, Baik SH, et al. The prevalence of metabolic syndrome in patients with gout: a multicenter study. J Korean Med Sci. 2005;20:1029-33.

9. Fraile JM, Torres RJ, de Miguel ME, Martinez P, Lundelin KJ, Vazquez JJ, et al. Metabolic syndrome characteristics in gout patients. Nucleosides Nucleotides Nucleic Acids. 2010;29:325-9.

10. Inokuchi T, Tsutsumi Z, Takahashi S, Ka T, Moriwaki Y, Yamamoto T. Increased frequency of metabolic syndrome and its individual metabolic abnormalities in Japanese patients with primary gout. J Clin Rheumatol. 2010;16:109-12

11. Yoo HG, Lee SI, Chae HJ, Park SJ, Lee YC, Yoo WH. Prevalence of insulin resistance and metabolic syndrome in patients with gouty arthritis. Rheumatol Int. 2011;31:485-91.

12. Choi HK, Ford ES, Li C, Curhan G. Prevalence of the metabolic syndrome in patients with gout: the Third National Health and Nutrition Examination Survey. Arthritis Rheum. 2007:57:109-15.

13. Novak S, Melkonian AK, Patel PA, Kleinman NL, Joseph-Ridge N, Brook RA. Metabolic syndrome-related conditions among people with and without gout: prevalence and resource use. Curr Med Res Opin. 2007;23:623-30.

14. Dao HH, Harun-Or-Rashid M, Sakamoto J. Body composition and metabolic syndrome in patients with primary gout in Vietnam. Rheumatology (Oxford). 2010;49:2400-7.

15. Tack CJ, Stienstra R, Joosten LA, Netea MG. Inflammation links excess fat to insulin resistance: the role of the interleukin-1 family. Immunol Rev. 2012:249:239-52.

16. Steering Committee of the WHO Western Pacific Region, IASO \& IOTF. The Asia-Pacific perspective: Redefining obesity and its treatment. Australia, 2000.

17. Third Report of the National Cholesterol Education Program (NCEP) Expert Panel on Detection, Evaluation, and Treatment of High Blood Cholesterol in Adults (Adult Treatment Panel III) final report. Circulation. 2002;106:3143-3421.

18. Choi HK, Atkinson K, Karlson EW, Curhan G. Obesity, weight change, hypertension, diuretic use, and risk of gout in men: the health professionals follow-up study. Arch Intern Med. 2005;165:742-8.

19. Bhole V, de Vera M, Rahman MM, Krishnan E, Choi H. Epidemiology of gout in women: Fifty-two-year follow-up of a prospective cohort. Arthritis Rheum. 2010;62:1069-76

20. Matsuura F, Yamashita S, Nakamura T, Nishida M, Nozaki S, Funahashi T, et al. Effect of visceral fat accumulation on uric acid metabolism in male obese subjects: visceral fat obesity is linked more closely to overproduction of uric acid than subcutaneous fat obesity. Metabolism. 1998;47:929-33.

21. Fox $\mathbb{H}$, John D, DeBruyne S, Dwosh I, Marliss EB. Hyperuricemia and hypertriglyceridemia: metabolic basis for the association. Metabolism. 1985;34:741-6.

22. Maury E, Brichard SM. Adipokine dysregulation, adipose tissue inflammation and metabolic syndrome. Mol Cell Endocrinol. 2010;314:1-16.

23. Hamdy O, Porramatikul S, Al-Ozairi E. Metabolic obesity: the paradox between visceral and subcutaneous fat. Curr Diabetes Rev. 2006;2:367-73.

24. He H, Ni Y, Chen J, Zhao Z, Zhong J, Liu D, et al. Sex difference in cardiometabolic risk profile and adiponectin expression in subjects with visceral fat obesity. Transl Res. 2010;155:71-7.

25. Joosten LA, Netea MG, Mylona E, Koenders MI, Malireddi RK, Oosting M, et al. Engagement of fatty acids with Toll-like receptor 2 drives interleukin-1 beta production via the ASC/caspase 1 pathway in monosodium urate monohydrate crystal-induced gouty arthritis. Arthritis Rheum. 2010;62:3237-48.

26. Stienstra R, Tack CJ, Kanneganti TD, Joosten LA, Netea MG. The inflammasome puts obesity in the danger zone. Cell Metabol. 2012;15:10-8.

27. Gheita TA, El-Fishawy HS, Nasrallah MM, Hussein H. Insulin resistance and metabolic syndrome in primary gout: relation to punched-out erosions. Int Rheum Dis. 2012;15:521-5.

28. Zhao Z, Nie H, He H, Yan Z, Liu D, Luo Z, et al. High-sensitivity C-reactive protein predicts target organ damage in Chinese patients with metabolic syndrome. Metabolism. 2007:56:1612-9.

29. Ogawa H, Fujitani K, Tsujinaka T, Imanishi K, Shirakata H, Kantani A, et al. InBody 720 as a new method of evaluating visceral obesity. Hepatogastroenterology. 2011;58:42-4. 
30. Ryo M, Maeda K, Onda T, Katashima M, Okumiya A, Nishida M, et al. A new simple method for the measurement of visceral fat accumulation by bioelectrical impedance. Diabetes Care. 2005;28:451-3.

31. Shaikh MG, Crabtree NJ, Shaw NJ, Kirk JM. Body fat estimation using bioelectrical impedance. Hormone Res. 2007;68:8-10.

32. Browning LM, Mugridge O, Chatfield MD, Dixon AK, Aitken SW, Joubert I, et al. Validity of a new abdominal bioelectrical impedance device to measure abdominal and visceral fat: comparison with MRI. Obesity (Silver Spring). 2010;18:2385-91.

Submit your next manuscript to BioMed Central and take full advantage of:

- Convenient online submission

- Thorough peer review

- No space constraints or color figure charges

- Immediate publication on acceptance

- Inclusion in PubMed, CAS, Scopus and Google Scholar

- Research which is freely available for redistribution 